\title{
Nitric oxide synthase activity in the olfactory bulb of anuran and urodele amphibians
}

Authors:

Angel Porteros, Rosario Arévalo, Carlos Crespo, Jesús G. Briñón, Eduardo Weruaga, José Aijón and José R. Alonso

Institutional affiliation:

Departamento de Biología Celular y Patología

Universidad de Salamanca

E-37007 Salamanca

Spain

Running head:

NOS in the amphibian OB

Correspondence to be sent to:

Dr. J.R. Alonso

Departamento de Biología Celular y Patología

Universidad de Salamanca. Facultad de Medicina

Avda. Campo Charro, 1

E-37007 Salamanca

Spain

phone: +34-23-294400 ext. 1854

fax: $+34-23-294549$

e-mail: jralonso@gugu.usal.es 


\section{ABSTRACT}

Nitric oxide synthase activity was studied by means of NADPH-diaphorase activity and nitric oxide synthase immunoreactivity in the main and accessory olfactory bulbs of the frog Rana perezi and the newt Triturus marmoratus. In both species, NADPH-diaphorase staining was observed in all olfactory fibers. Vomeronasal fibers were NADPHdiaphorase labeled in Triturus but they were NADPH-diaphorase negative in Rana. Nitric oxide synthase immunoreactivity was not observed in the primary afferents in any case. Granule cells were NADPH-diaphorase positive and nitric oxide synthase immunopositive in the main and accessory olfactory bulb of Rana, and in the main olfactory bulb of Triturus. The homogeneous NADPH-diaphorase staining of olfactory fibers is similar to what has been reported in teleosts, and it contrasts with the spatial segregation of NADPH-diaphorase positive and negative olfactory projections in rodents. These results confirm the interspecies variability of the NADPH-diaphorase/nitric oxide synthase distribution in the olfactory system of vertebrates.

\section{KEY WORDS}

Anamniote, NADPH-diaphorase, nitric oxide synthase, olfactory system 


\section{INTRODUCTION}

The NADPH-diaphorase (ND) histochemical reaction produces a Golgi-like labeling of specific neuronal populations containing nitric oxide synthase (NOS) in all major areas of the mammalian brain ${ }^{7,19}$. In the olfactory bulb (OB), a total coincidence in the distribution of ND-activity and NOS-immunoreactivity has been described in specific subpopulations of interneurons, but no evidence of NOS-immunoreactivity was found in the primary afferences, despite their strong ND-activity 22 .

ND and NOS labeling has been described in the OB of mammals: rat ${ }^{12}$, hamster ${ }^{12}$, mouse $^{22}$, and hedgehog ${ }^{2}$. Important differences in the ND/NOS staining pattern have been observed in these species 2,12 , suggesting differences in the modulatory mechanisms in which this enzyme is involved.

Previous studies on the distribution of ND activity and NOS immunoreactivity in non-mammalian vertebrates reported that the ND staining in the OB of teleost fish ${ }^{5,18}$ was substantially different to what has been observed in mammals. ND activity has been also investigated in the Japanese quail $\mathrm{OB}^{27}$ and it was found to be completely negative. ND activity has been reported in the $\mathrm{OB}$ of the salamander ${ }^{33}$ but no comprehensive study of the distribution of this enzyme in the amphibian OB using both ND histochemistry and NOS immunoreactivity has been carried out.

Amphibians have an olfactory system with both primitive and advanced characters. As an ancestral character, amphibian mitral cells do not appear in a monolayer and posses several branched glomerular dendrites ${ }^{29}$, as in fish ${ }^{4}$ and birds 6 . By contrast, a unique dendrite makes synapses with olfactory receptor cell axons in mammalian mitral cells ${ }^{4}$, indicating a higher degree of convergence of olfactory inputs. Furthermore, the axons of the mitral cells of amphibians project through two segregated fiber tracts with different targets $^{30}$. Two independent olfactory tracts are also present in the teleost olfactory system $^{6}$, whereas only the lateral olfactory tract is present in mammals ${ }^{1}$. Otherwise, the amphibian OB presents some advanced features. Thus, amphibians are the first vertebrate 
group during evolution with a separate accessory olfactory system ${ }^{1}$. Periglomerular cells ${ }^{1}$ and tufted cells 4,29 are characterized as neuronal types in the amphibian OB circuitry, and amphibian mitral cells have two types of dendrites with different morphology and synaptic connections ${ }^{4,29}$. The above cited characteristics make the amphibian OB an adequate system where try to understand the interspecies variability in the ND/NOS staining.

In this report we studied the distribution of ND activity and NOS immunoreactivity in the main olfactory bulb (MOB) and accessory olfactory bulb (AOB) of the frog Rana perezi (Anura) and the newt Triturus marmoratus (Urodela). The analysis of the possible similarities and/or differences with the staining observed in other classes of vertebrates may provide valuable information on the evolution of ND/NOS system in the vertebrate olfactory pathway.

\section{MATERIALS AND METHODS}

Six adult frogs (Rana perezi) weighing 40-60 g, and six adult newts (Triturus marmoratus), weighing 30-50 g, of either sex, were captured in the wild and used for this study. After deep anesthesia with $0.03 \%$ tricaine methanosulfonate (MS-222, Sandoz) in water, the animals were perfused through the conus arteriosus with $25 \mathrm{ml}$ heparinized saline solution followed by $150 \mathrm{ml}$ of a fixative containing 4\% paraformaldehyde and 15\% saturated picric acid in 0.1 M phosphate buffer, pH 7.4 (PB). After removal from the skull and immersion for 4 hours in perfusate, the olfactory bulbs and telencephalic hemispheres were dissected out and stored overnight in 30\% (vol./vol.) sucrose for cryoprotection. The tissue was quickly frozen with liquid nitrogen and $30 \mu \mathrm{m}$ horizontal sections were cut on a cryostat (Bright) at $-21^{\circ} \mathrm{C}$. The sections were washed in $\mathrm{PB}$ and processed for ND histochemistry during $90-120$ minutes at $37^{\circ} \mathrm{C}$ as described elsewhere ${ }^{3}$. The incubation medium was made up of $1 \mathrm{mM} ß-\mathrm{NADPH}$ (Sigma), $0.3 \mathrm{mM}$ nitro blue tetrazolium (Sigma) and $0.1 \%$ Triton $\mathrm{X}-100$ in $0.1 \mathrm{M} \mathrm{PB}, \mathrm{pH}$ 7.6. The course of the reaction was controlled under the microscope, and it was stopped with several rinses in cold $\left(4^{\circ} \mathrm{C}\right) \mathrm{PB}$. 
After the histochemical reaction, some ND-stained sections were processed for NOS immunocytochemistry. Sections were sucesively incubated in a) primary antibody (K205 sheep anti-rat neuronal NOS antibody ${ }^{11}$ ) diluted 1:20000 in PB during three days at $4^{\circ} \mathrm{C}$, and b) fluorescein-labeled anti-sheep serum (Vector) diluted 1:50 in PB during $1 \mathrm{~h}$ at room temperature.

The K205 neuronal NOS antibody has been fully characterized. Specificity of the antibody was assessed using Western blott analysis and liquid phase pre-adsorption experiments with purified recombinant neuronal NOS 16 .

Controls of the specificity for both the histochemical and immunocytochemical procedures were carried out as previously described 2,3 . No residual reaction was observed.

The sections were mounted on gelatinized glass slides, dehydrated in a graded ethanol series, cleared with xylene and coverslipped with Entellan (Merck). Labelled cells wre identified in a Zeiss III photomicroscope equipped with epifluorescence and appropriate filter sets. Cell sizes were measured using a Zeiss ocular micrometer.

\section{RESULTS}

Both Rana perezi and Triturus marmoratus have well-developed paired OB at the rostral pole of the telencephalon. In Rana perezi, left and right MOB are fused on their medial side (Fig. 2a), whereas in Triturus marmoratus, they are separated (Fig. 2b). In both species, the AOB is located lateral and caudal to the MOB. After the histochemical reaction, ND activity was observed as a pale to dark blue formazan filling in specific neurons and/or fibers in the $\mathrm{MOB}$ and $\mathrm{AOB}$ of both species. Figure 1 shows the distribution of ND-labeled elements in the MOB and AOB of both amphibians species. In order to allow the comparison with the ND staining present in the OB of higher vertebrates, a scheme of the ND labeling in the rat OB is provided in the same figure.

After double labeling with ND histochemistry and NOS immunocytochemistry, a total colocalization of both markers was found in positive interneurons, but only strong 
ND-activity was observed in the stained primary afferents that were NOSimmunonegative.

In the MOB of Rana perezi, all olfactory fibers and glomeruli were ND-active. The strongly ND-stained olfactory nerves were observed penetrating separately into the OB (Fig. 2a). They diverged in small bundles that arborize in row-shaped glomeruli (Fig. 2c) arranged in several rows, forming a wide glomerular layer. The staining intensity was quite homogeneous in all fibers and glomeruli, and no ND-negative olfactory fibers or glomeruli could be seen.

Rarely, ND/NOS stained varicose fibers were observed coursing from the granule cell layer to the external plexiform layer (Fig 2c). These thin processes were identified as centrifugal afferents to the glomerular layer of the MOB. In addition, scattered ND-active and NOS-immunoreactive neurons were observed in the granule cell layer (Fig. 2d,e). These cells were slightly stained, small (7 to $10 \mu \mathrm{m}$ in diameter), spherical or piriform in shape. In some occasions, one or two slightly stained processes could be seen. According to these morphological characteristics, these small neurons were identified as granule cells.

In the AOB of Rana perezi, no staining appeared in the vomeronasal fibers and glomeruli (Fig. 2a). By contrast, abundant granule cells were ND-positive and NOSimmunoreactive, and their stained dendrites could be followed along the granule cell and external plexiform layers of the AOB (Fig. 2f).

In Triturus marmoratus, all olfactory fibers were ND-positive and NOSimmunonegative. The olfactory fibers arborized in glomeruli of larger size (60 to $80 \mu \mathrm{m}$ in diameter) than the olfactory glomeruli observed in Rana perezi (diameters ranging 35-50 $\mu \mathrm{m})$. The ND staining intensity was strong, and no negative fiber bundles or glomeruli were observed (Fig. 2b). In the granule cell layer, very scarce ND-positive and NOS immunoreactive cells appeared (Fig. 2g,h). These cells had similar shape but they were larger (about 10-15 $\mu \mathrm{m}$ in diameter) than those observed in Rana perezi, and stained dendrites were less evident. Contrary to what was observed in Rana perezi, vomeronasal 
fibers and glomeruli were ND-positive (Fig. 2b), whereas the granule cells of the AOB of Triturus marmoratus were always ND- and NOS-negative.

\section{DISCUSSION}

Both similarities and differences in the distribution of ND-active and NOSimmunoreactive elements can be observed between both species of amphibians studied. The labeling was similar in the MOB, but it showed interspecies differences in the AOB. Whereas the ND-labeled elements in the AOB of Triturus marmoratus were vomeronasal afferences, the ND/NOS positive elements in the AOB of Rana perezi were intrinsic neurons, identified as granule cells. Both vomeronasal fibers and granule cells make synaptic contacts with the AOB mitral cells ${ }^{10}$, constituting the main modulation circuit of the chemosensory response in this brain area. The differential ND and NOS staining observed in Rana perezi and Triturus marmoratus suggests that different nitrergic modulatory mechanisms are present in the AOB of either anurans or urodeles.

Comparing our data in the amphibian MOB with previous studies of the ND distribution in the OB of other groups of vertebrates $2,5,12,18,22,27$, important interspecies differences can be noted. In all mammalian species hitherto studied only those olfactory fibers and glomeruli located in the dorsomedial surface of the MOB demonstrated ND labeling, whereas ventrolateral glomeruli were ND-negative2,12,22. By contrast, in birds, all olfactory fibers were negative ${ }^{27}$ whereas in teleosts, all of them demonstrated ND staining5,18. In our material, all olfactory fibers of both Rana perezi and Triturus marmoratus displayed ND-activity. By contrast, a heterogeneus ND-labeling in the olfactory glomeruli of Salamandra has been previously reported ${ }^{33}$.

Periglomerular cells have been identified as ND-active and NOS-immunoreactive in the OB of mammals2,12,22. Periglomerular cells do exist in the OB of both anurans and urodeles $^{4}$, being observed after immunocytochemistry against catecholamines and 
somatostatin $^{20}$, and $\gamma$-aminobutyric acid ${ }^{14}$, but they were ND/NOS-negative in the $\mathrm{OB}$ of both Rana perezi and Triturus marmoratus.

Scarce ND/NOS-stained granule cells were observed in the OB of both Rana perezi and Triturus marmoratus. Granule cells are the most numerous neurons in the OB of all classes of vertebrates ${ }^{1}$. Subpopulations of granule cells have been observed in the OB of mammals after ND histochemistry and NOS immunocytochemistry, with interspecies differences in their relative density 2,12 . In all species of mammals studied, ND/NOS-positive granule cells outnumbered those observed in the amphibian OB. By contrast, ND/NOS-positive granule cells were not observed in both the tench (Tinca tinca $)^{5}$ and the Atlantic salmon (Salmo salar) ${ }^{18}$. With respect to microsmatic vertebrates, ND/NOS activity was observed in neither olfactory fibers nor intrinsic interneurons in the OB of the Japanese quail 27.

ND activity or NOS-immunoreactive labeling has been described in the AOB of rat $^{12,28}$, mouse ${ }^{22}$, hamster ${ }^{12}$ and hedgehog 2 . Only partial coincidences exist with the labeling observed in the amphibian AOB. Vomeronasal afferences were ND-positive in mammals and in Triturus marmoratus. Otherwise, abundant granule cells were NDpositive in Rana perezi and in the mammalian AOB. Scarce ND/NOS-positive periglomerular cells have been observed in the rat 28 and hedgehog 2 AOB whereas this cellular type was always ND-negative in the AOB of both amphibian species.

Along the phylogenetic scale, amphibians showed intermediate ND/NOS staining between the simple labeling observed in teleosts and the variety of positive elements in the OB of macrosmatic mammals, whereas the staining disappears in the secondary simplified avian OB. Although the general structure of the $\mathrm{OB}$ is common in all vertebrates ${ }^{1}$, the nitrergic pattern seems to be more complex in vertebrate groups with a higher degree of organization of their olfactory system and more important significance of olfaction in their physiology.

Studies on the functional organization of the projections from the olfactory receptor cells to the MOB of amphibians have been carried out by means of tract-tracing 
methods ${ }^{13}$, immunocytochemical markers ${ }^{21}$ and selective lectin-binding ${ }^{17}$. All these works revealed the existence of a spatial-specific projection from subsets of neurochemically heterogeneous olfactory receptor cells to the MOB. In mammals, subclasses of olfactory receptor cells and their projections to the MOB have been selectively labeled with monoclonal antibodies against superficial carbohydrate epitopes $^{26,31}$. It has been proposed that the selective ND staining of olfactory fibers and glomeruli observed in the MOB of mammals correlates with the functional significance of specific groups of receptors $^{9}$. In this sense, some of the immunocytochemically-defined subgroups of receptors project in a similar ${ }^{31}$ or complementary ${ }^{26}$ spatial pattern to the location of ND labeling in the glomerular layer of the MOB. However, our data in the amphibian OB do not support this hypothesis. Different functional subclasses of olfactory receptors with spatial specificity in their connections have been previously described in amphibians ${ }^{17}$. In spite of this, olfactory receptors seemed to be homogeneous with respect to their ND staining, and no topographical organization of ND staining was observed in the olfactory projection of Triturus marmoratus and Rana perezi.

The absence of total coincidence of ND with NOS has been previously reported in amphibians, at least in the retina 24 . In this sense, we have observed a total colocalization of both activities in granule cells of Rana perezi and Triturus marmoratus, but not in the primary afferents that were ND-positive and NOS-immunonegative. These results are in agreement with Kishimoto et al. ${ }^{22}$, who observed in the mouse OB that ND and NOS were coincident in intrinsic interneurons, but they did not find NOS immunoreactivity or NOS mRNA signal in olfactory or vomeronasal glomeruli, despite their strong ND activity. Similar results have been obtained in the OB of the Atlantic salmon, Salmo salar 18, where ND-positive labeling was observed in the olfactory fibers but they were NOSimmunonegative.

These results indicates that ND is not equivalent to NOS in the olfactory and vomeronasal projections. A role for nitric oxide has been postulated in the olfactory cilia 25 and terminals 9 of olfactory receptor cells, hypothesis that requires the presence of a NOS 
in the region of transduction of the odour stimuli. NOS immunoreactivity has been observed in perivascular nerve fibers ${ }^{15,23}$, suggesting that NO may modulate olfactory sensory transduction through perireceptor events. The enzyme responsible of the NDactivity displayed by the amphibian olfactory and vomeronasal axons may be cytochrome $\mathrm{P} 45 \mathrm{O}$ reductase, as is the case in mammals. This enzyme has been immunocytochemically demonstrated in the olfactory and vomeronasal receptor cells 22,32 and demonstrates a close homology with NOS $^{8}$.

\section{ACKNOWLEDGMENTS}

The authors want to express their gratitude to Drs. Emson and Charles for kindly providing the anti-NOS antibody used in this study. This work was supported by grants from the Junta de Castilla y León, and the DGICyT (PB94-1388 and PR95-350). 


\section{REFERENCES}

1. Allison, A.C., The morphology of the olfactory system in the vertebrates, Biol. Rev., 28 (1953) 195-244.

2. Alonso, J.R., Arévalo, R., García-Ojeda, E., Porteros, A., Briñón, J.G. and Aijón, J., NADPH-diaphorase active and calbindin D-28k-immunoreactive neurons and fibers in the olfactory bulb of the hedgehog (Erinaceus europaeus), J. Comp. Neurol., 351 (1995) 307-327.

3. Alonso, J.R., Arévalo, R., Porteros, A., Briñón, J.G., García-Ojeda, E. and Aijón, J., NADPH-diaphorase histochemical technique in the brain, Neurosci. Protocols., (1995)

4. Andres, K.H., Anatomy and ultrastructure of the olfactory bulb in fish, amphibia, reptiles, birds and mammals. In G.E. Wolstenholme and J. Knight (Eds.), Ciba Foundation Symposium on Taste and Smell in vertebrates, Churchill, London, 1970, pp. 177-196.

5. Arévalo, R., Alonso, J.R., García-Ojeda, E., Briñón, J.G., Crespo, C. and Aijón, J., NADPH-diaphorase in the central nervous system of the tench, (Tinca tinca L., 1758), J. Comp. Neurol., 352 (1995) 398-420.

6. Ariens-Kappers, C.U., Huber, C.C. and Crosby, E.C., The comparative anatomy of the nervous system of the vertebrates. 1936, New York: Hafner Publishing Co.

7. Bredt, D.S., Glatt, C.E., Hwang, P.M., Fotuhi, M., Dawson, T.M. and Snyder, S.H., Nitric oxide synthase protein and mRNA are discretely localized in neuronal populations of the mammalian CNS together with NADPH diaphorase, Neuron, 7 (1991) 615-624. 
8. Bredt, D.S., Hwang, P.M., Glatt, C.E., Lowenstein, C., Reed, R.R. and Snyder, S.H., Cloned and expressed nitric oxide synthase structurally resembles cytochrome P-450 reductase, Nature, 351 (1991) 714-718.

9. Breer, H. and Shepherd, G.M., Implications of the NO/cGMP system for olfaction, Trends Neurosci., 16 (1993) 5-9.

10. Burton, P.R., Vomeronasal and olfactory nerves of adult and larval bullfrogs: II. Axon terminations and synaptic contacts in the accessory olfactory bulb, J. Comp. Neurol., 292 (1990) 624-637.

11. Charles, I.G., Chubb, A., Gill, R., Clare, J., Lowe, P.N., Holmes, L.S., Page, M., Keeling, J.G., Moncada, M. and Riveros-Moreno, V., Cloning and expression of rat neuronal nitric oxide synthase coding sequence in a baclovirus/insect cell system, Biochem. Biophys. Res. Comm., 196 (1993) 1481-1489.

12. Davis, B.J., NADPH-diaphorase activity in the olfactory system of the hamster and rat, J. Comp. Neurol., 314 (1991) 493-511.

13. Duncan, H.J., Nickell, W.T., Shipley, M.T. and Gesteland, R.C., Organization of projections from olfactory epithelium to olfactory bulb in the frog, Rana pipiens, J. Comp. Neurol., 299 (1990) 299-311.

14. Hamilton, K.A., Distribution of immunoreactivity for $\gamma$-aminobutyric acid in the salamander olfactory bulb, J. Comp. Neurol., 319 (1992) 606-614. 
15. Hanazawa, T., Konno, A., Kaneko, T., Tanaka, K., Ohshima, H., Esumi, H. and Chiba, T., Nitric oxide synthase-immunoreactive nerve fibers in the nasal mucosa of the rat, Brain Res., 657 (1994) 7-13.

16. Herbison, A.E., Simonian, S.X., Norris, P.J. and Emson, P.C., Relationship of neuronal nitric oxide synthase immunoreactivity to GnRH neurons in the ovariectomized and intact female rat, J. Neuroendocrinol., 8 (1996)

17. Hofmann, M.H. and Meyer, D.L., Functional subdivisions of the olfactory system correlate with lectin-binding properties in Xenopus, Brain Res., 564 (1991) 344-347.

18. Holmqvist, B.I., Östholm, T., Alm, P. and Ekström, P., Nitric oxide synthase in the brain of a teleost, Neurosci. Lett., 171 (1994) 205-208.

19. Hope, B.T., Michael, G.J., Knigge, K.M. and Vincent, S.R., Neuronal NADPHdiaphorase is a nitric oxide synthase, Proc. Natl. Acad. Sci. USA, 88 (1991) 2811-2814.

20. Inagaki, S., Shiosaka, S., Takatsuki, K., Sakanaka, M., Takagi, H., Senba, E., Matsuzaki, T. and Tohyama, M., Distribution of somatostatin in the frog brain, Rana catesbeiana, in relation to location of catecholamine-containing neurons, J. Comp. Neurol., 202 (1981) 89-101.

21. Key, B. and Akeson, R.A., Delineation of olfactory pathways in the frog nervous system by unique glycoconjugates and N-CAM glycoforms, Neuron, 6 (1991) 381-396.

22. Kishimoto, J., Keverne, E.B., Hardwick, J. and Emson, P.C., Localization of nitric oxide synthase in the mouse olfactory and vomeronasal system: a histochemical, immunological and in situ hybridization study, Eur. J. Neurosci., 5 (1993) 1684-1694. 
23. Kulkarni, A.P., Getchell, T.V. and Getchell, M.L., Neuronal nitric oxide synthase is localized in extrinsic nerves regulating perireceptor processes in the chemosensory nasal mucosae of rats and humans, J. Comp. Neurol., 345 (1994) 125-138.

24. Liepe, B.A., Stone, C., Koistinaho, J. and Copenhagen, D.R., Nitric oxide synthase in Müller cells and neurons of salamander and fish retina, J. Neurosci., 14 (1994) 76417654.

25. Lischka, F.W. and Schild, D., Effects of nitric oxide upon olfactory receptor neurones in Xenopus laevis, Neuroreport, 4 (1993) 582-584.

26. Mori, K., Fujita, S.C., Imamura, K. and Obata, K., Immunohistochemical study of subclasses of olfactory nerve fibers and their projections to the olfactory bulb in the rabbit, Neuroscience, 20 (1985) 259-278.

27. Panzica, G.C., Arévalo, R., Sánchez, F., Alonso, J.R., Aste, N., Viglietti-Panzica, C., Aijón, J. and Vázquez, R., Topographical distribution of reduced nicotinamide adenine dinucleotide phosphate-diaphorase in the brain of the Japanese quail, J. Comp. Neurol., 342 (1994) 97-114.

28. Porteros, A., Alonso, J.R., Arévalo, R., García-Ojeda, E., Crespo, C. and Aijón, J., Histochemical localization of NADPH-diaphorase in the rat accessory olfactory bulb, Chem. Senses, 19 (1994) 413-424.

29. Scalia, F., Gallousis, G. and Roca, S., A note on the organization of the amphibian olfactory bulb, J. Comp. Neurol., 305 (1991) 435-442. 
30. Scalia, F., Gallousis, G. and Roca, S., Differential projections of the main and accessory olfactory bulb in the frog, J. Comp. Neurol., 305 (1991) 443-461.

31. Schwarting, G.A. and Crandall, J.E., Subsets of olfactory and vomeronasal sensory epithelial cells and axons revealed by monoclonal antibodies to carbohydrate antigens, Brain Res., 547 (1991) 239-248.

32. Voigth, J.M., Guengerich, F.P. and Baron, J., Localization and induction of cytochrome P450 1A1 and aryl hydrocarbon hydroxylase activity in rat nasal mucosa, $J$. Histochem. Cytochem., 41 (1993) 877-885.

33. Zhao, H., Firestein, S. and Greer, C.A., NADPH-diaphorase localization in the olfactory system, Neuroreport, 6 (1994) 149-152. 


\section{FIGURE LEGENDS}

\section{Figure 1}

Schematic drawing of ND- and NOS-labeled elements in the main and accessory olfactory bulb of newt, frog, and rat.

AOB: Accessory olfactory bulb. DSA: Deep short-axon cell. EPL: External plexiform layer. GC: Granule cell. GCL: Granule cell layer. GL: Glomerular layer. HZ: Horizontal cell. IPL: Internal plexiform layer. MCL: Mitral cell layer. MOB: Main olfactory bulb. PG: Periglomerular cell. SSA: Superficial short-axon cell.

\section{Figure 2}

ND activity in the amphibian olfactory bulb. AOB: Accessory olfactory bulb. MOB: Main olfactory bulb. Scale bars in a,b=500 $\mu \mathrm{m}$; in c-h=50 $\mu \mathrm{m}$

a: Intense ND staining in the olfactory fibers and glomeruli of the frog Rana perezi. Note the absence of staining in the vomeronasal fibers and glomeruli and the homogeneus labeling in the granule cell layer of the AOB. Horizontal section.

b: Horizontal section of the olfactory bulb of the newt Triturus marmoratus. Both olfactory and vomeronasal fibers were ND-active.

c: ND staining in the superficial layers of the MOB of Rana perezi. Intensely stained glomeruli (G) and centrifugal fibers (arrows) can be seen.

d: NOS-immunofluorescent granule cell in the MOB of Rana perezi.

e: ND labeling in the same field as in (d). ND activity colocalizes with NOS immunoreactivity in the same cell.

f: Granule cell layer of the AOB of Rana perezi. ND-labeled somata and fibers can be observed. V: Ventricle. 
NOS in the amphibian $O B$

g: NOS-immunofluorescent granule cell in the MOB of Triturus marmoratus.

h: ND labeling in the same field as in (g). ND activity colocalizes with NOS immunoreactivity in the same cell. 

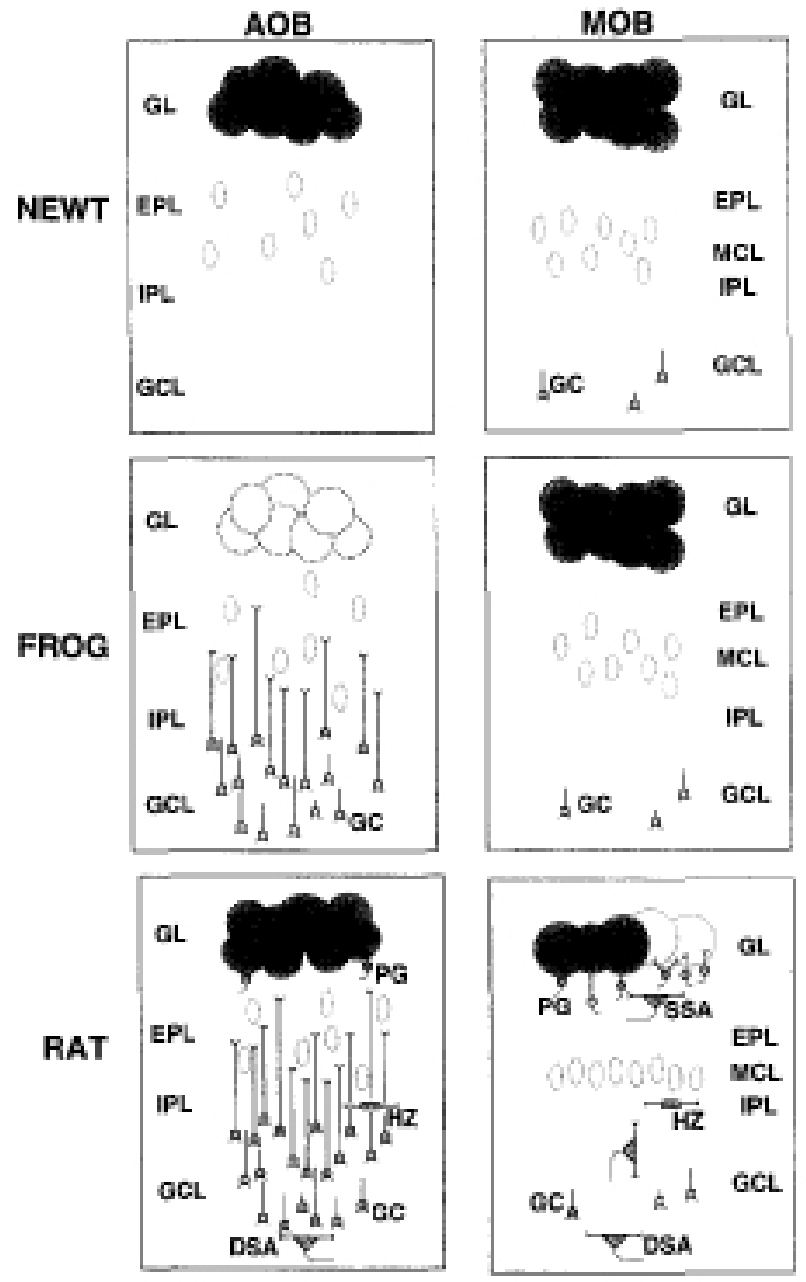
